\title{
Photocatalytic hydrogen generation with Ag-loaded $\mathrm{LiNbO}_{3}$
}

\author{
BEATA ZIELIŃSKA* \\ Institute of Chemical and Environment Engineering, West Pomeranian University of Technology, \\ Szczecin, Pułaskiego 10, 70-322 Szczecin, Poland
}

MS received 26 April 2013; revised 20 September 2013

\begin{abstract}
In this contribiution $\mathrm{LiNbO}_{3}$ and $\mathrm{Ag}$-loaded $\mathrm{LiNbO}_{3}$ photocatalysts were tested in the reaction of hydrogen evolution. The silver modified samples contained different loading of co-catalyst in the range of $0.5-4 \mathrm{wt} \%$. It was essential to optimize the sample composition to achieve an efficient hydrogen evolution. The optimal sample contained $2 \mathrm{wt} \%$ of silver. The detailed analysis indicated that silver was deposited on the surface of $\mathrm{LiNbO}_{3}$ in the form of $\mathrm{Ag}_{2} \mathrm{O}$. Therefore, it is supposed that $\mathrm{Ag}_{2} \mathrm{O}$ was responsible for the enhanced photocatalytic activity in the studied reaction. The crystallographic phases and optical and vibronic properties were examined by X-ray diffraction (XRD) and diffuse reflectance (DR) UV-Vis and resonance Raman spectroscopic methods, respectively. Morphology of the produced samples were studied using a highresolution transmission electron microscope (HRTEM).
\end{abstract}

Keywords. Lithium niobate; $\mathrm{Ag}_{2} \mathrm{O}$; photocatalysts; hydrogen evolution.

\section{Introduction}

Lithium niobate $\left(\mathrm{LiNbO}_{3}\right)$ is one of the most excellent functional materials due to its outstanding physical properties such as piezoelectrical, electrooptical, pyroelectrical and photorefractive properties. It has useful applications for surface acoustic wavedevices, waveguides in integrated optics, infracted sensors, etc (An et al 2002; Simoes et al 2003; Liu and Xue 2006; Hao et al 2009; Chen et al 2012). On the other hand, it fully fills all requirements (such as flat band potential and the number of photons absorbed) of a good potential as a photocatalyst for hydrogen generation. However, there are only few reports investigating the photocatalytic properties of $\mathrm{LiNbO}_{3}$ (Chen et al 2004; Saito et al 2011; Stock and Dunn 2012). Chen et al (2004) reported that $\mathrm{LiNbO}_{3}$ synthesized via solid-state reaction was active in the reaction of photocatalytic hydrogen generation in the presence of methanol. Saito et al (2011) stated that $\mathrm{LiNbO}_{3}$ nanowires produced by a metal complex-based method showed good photocatalytic activity for water splitting. Moreover, they found that $\mathrm{LiNbO}_{3}$ nanowires showed enhanced photocatalytic properties as compared with $\mathrm{LiNbO}_{3}$ prepared by a solid-state reaction. Additionally, the activity of $\mathrm{LiNbO}_{3}$ and $\mathrm{Fe}$ - and $\mathrm{Mg}$-doped $\mathrm{LiNbO}_{3}$ in the reaction of photocatalytic acid black 1 and rhodamine B decomposition under solar illumination was also reported (Stock and Dunn 2012). In this study, the authors point out that $\mathrm{LiNbO}_{3}$ is an active photocatalyst for organic dyes decomposition under solar irradiation

*Author for correspondence (bzielinska@zut.edu.pl) and $\mathrm{Mg}$-doped $\mathrm{LiNbO}_{3}$ exhibits higher photocatalytic activity than pure $\mathrm{LiNbO}_{3}$. In our previous work (Zielińska et al 2008), several chemical compounds based lithium niobate prepared via impregnation followed by calcination were tested in the reaction of photocatalytic hydrogen generation. The results indicated that the most active catalyst for the photocatalytic generation of hydrogen is the one containing two lithium niobate phases: $\mathrm{LiNbO}_{3}$ and $\mathrm{LiNb}_{3} \mathrm{O}_{8}$.

It is known that loading co-catalysts on the surface of photocatalysts is often essential for achieving efficient hydrogen evolution. The loaded co-catalysts can capture the photogenerated electrons reducing the electron-hole recombination and act as reaction sites for proton reduction (Kudo 2006; Chen et al 2010; Puangpetch et al 2010; $\mathrm{Yu}$ et al 2011). For example, Yu et al (2011) stated that $\mathrm{CuO}$ is effective co-catalyst for $\mathrm{TiO}_{2}$ to enhance the photocatalytic hydrogen production. The amount of hydrogen obtained in the presence of $1.3 \mathrm{wt} \% \mathrm{CuO} / \mathrm{TiO}_{2}$ was about 129 times greater than that in the presence of pure $\mathrm{TiO}_{2}$. Kudo (2006) studied photodecomposition of water in the presence of many different tantalate photocatalysts. The author indicated that loading with NiO cocatalyst, which works as $\mathrm{H}_{2}$ evolution site, drastically improves the photocatalytic activity of tantalates. The activity of $\mathrm{SrTiO}_{3}$ with different loaded metal co-catalysts $(\mathrm{Au}, \mathrm{Pt}, \mathrm{Ag}, \mathrm{Ni}, \mathrm{Ce}$ and $\mathrm{Fe}$ ) in the reaction of photocatalytic hydrogen production from a methanol aqueous solution was studied (Puangpetch et al 2010). Here, the authors stated that $\mathrm{Au}, \mathrm{Pt}, \mathrm{Ag}$ and $\mathrm{Ni}$ loadings have a positive effect on the photocatalytic activity of $\mathrm{SrTiO}_{3}$ under both UV and Vis light irradiation. 
In the present study, the synthesis, characterization and photocatalytic properties of unmodified $\mathrm{LiNbO}_{3}$ and Ag-loaded $\mathrm{LiNbO}_{3}$ for the reaction of photocatalytic hydrogen generation will be presented. The influence of silver content on the photocatalytic activity of $\mathrm{Ag} /$ $\mathrm{LiNbO}_{3}$ materials for photocatalytic hydrogen generation has been investigated. The photocatalytic reactions were carried out in the presence of formic acid.

\section{Experimental}

\subsection{Preparation of $\mathrm{LiNbO}_{3}$ and $\mathrm{Ag}$-loaded $\mathrm{LiNbO}_{3}$ photocatalysts}

All the initial reagents, $\mathrm{Nb}_{2} \mathrm{O}_{5}, \mathrm{LiOH} \cdot \mathrm{H}_{2} \mathrm{O}$ and $\mathrm{AgNO}_{3}$ were used as received without further purification (SigmaAldrich). In a typical synthesis, first $\mathrm{Nb}_{2} \mathrm{O}_{5}$ was dissolved in an aqueous solution of lithium hydroxide with vigorous stirring. The molar ratio of $\mathrm{LiOH}: \mathrm{Nb}_{2} \mathrm{O}_{5}$ was $2: 1$, respectively. After the addition of $\mathrm{Nb}_{2} \mathrm{O}_{5}$, the mixture was continually stirred for $3 \mathrm{~h}$ above the boiling temperature. The solid material was dried at the temperature of $70{ }^{\circ} \mathrm{C}$ and grounded in a mortar until the fine powder was obtained. Next, the sample was calcined in the temperature of $550{ }^{\circ} \mathrm{C}$ in air for a controlled time between 5 to $20 \mathrm{~h}$ with step of $5 \mathrm{~h}$. Finally, the excess of $\mathrm{LiOH}$ was washed out with water.

Silver was loaded as a co-catalyst on the produced $\mathrm{LiNbO}_{3}$ by conventional impregnation/calcination procedure. Typically, $\mathrm{LiNbO}_{3}$ powder was introduced to the aqueous solution of silver nitrate and stirred vigorously until the homogeneous suspension was observed. During the experimental procedure the samples with Ag loading in the range of $0.5-4 \mathrm{wt} \%$ were prepared. Water was evaporated during the slow heating and constant stirring. The resulting products were dried at $70^{\circ} \mathrm{C}$ for $24 \mathrm{~h}$ and then calcined at $400{ }^{\circ} \mathrm{C}$ for $4 \mathrm{~h}$.

\subsection{Photocatalysts characterization}

The crystallographic structures of the prepared samples were confirmed by X-ray diffraction analysis (X'Pert PRO Philips diffractometer, $\operatorname{CoK} \alpha$ radiation). UV-Vis diffuse reflectance spectra were recorded using a UV-Vis spectrometer (Jasco, Japan). Raman measurements were performed using a Resonance Raman Renishaw In Via Microscope spectrometer with a laser length of $785 \mathrm{~nm}$. The morphology of the photocatalysts was investigated by high-resolution transmission electron microscopy (HR-TEM-FEI Tecnai F30).

\subsection{Photocatalytic reactions}

The photocatalytic reactions were carried out at room temperature under atmospheric pressure in a closed system with an inner irradiation-type photoreactor using a $\mathrm{Hg}$ lamp $(150 \mathrm{~W})$. The rate of $\mathrm{H}_{2}$ evolution was determined in an aqueous solution of $0.1 \mathrm{M}$ formic acid

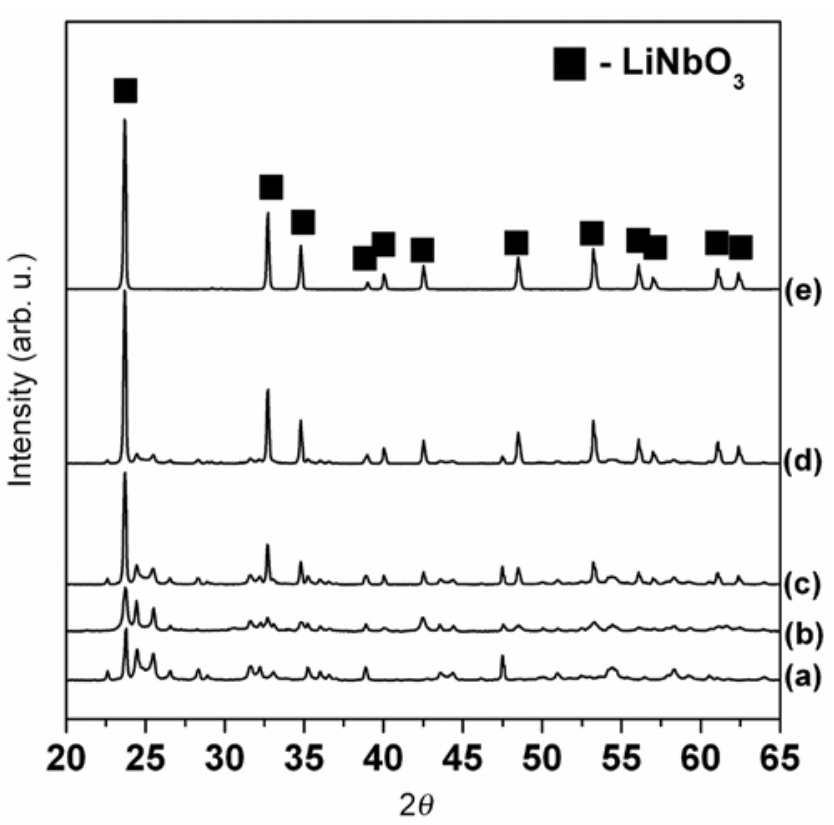

Figure 1. XRD patterns of $\mathrm{Nb}_{2} \mathrm{O}_{5}$ (a) and material produced after calcination of $\mathrm{Nb}_{2} \mathrm{O}_{5}$ and $\mathrm{LiOH}$ at temperature of $550{ }^{\circ} \mathrm{C}$ for $5,10,15$ and $20 \mathrm{~h}(\mathbf{b}-\mathbf{e})$.

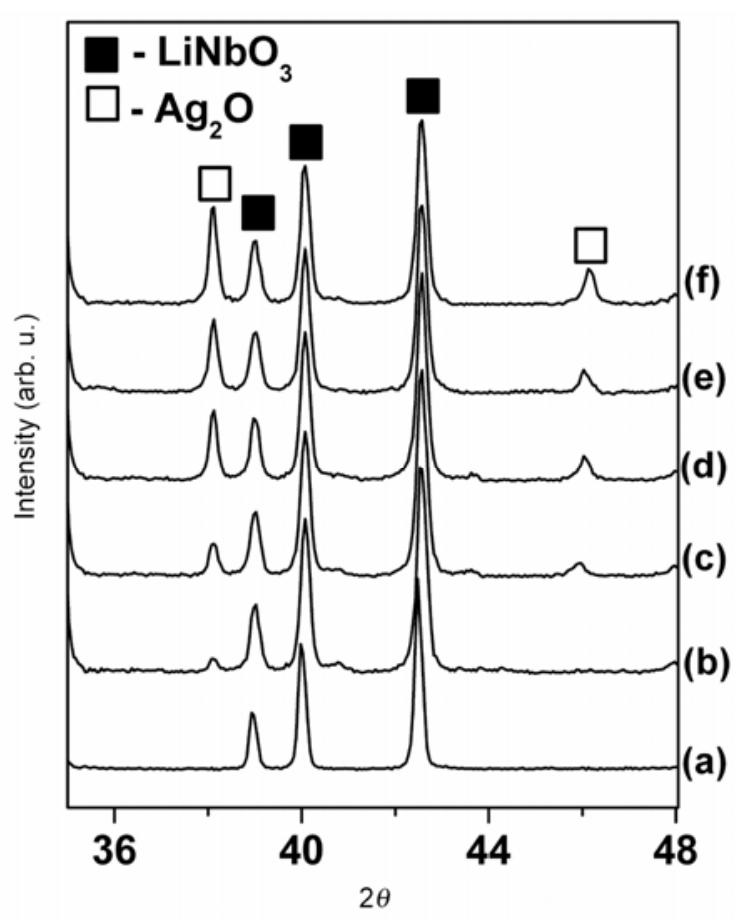

Figure 2. $\mathrm{XRD}$ patterns of $\mathrm{LiNbO}_{3}$ (a) and Ag-loaded $\mathrm{LiNbO}_{3}$ with $0 \cdot 5$ (b), 1 (c), 2 (d), 3 (e) and 4 (f) $\mathrm{wt} \%$ of $\mathrm{Ag}$. 

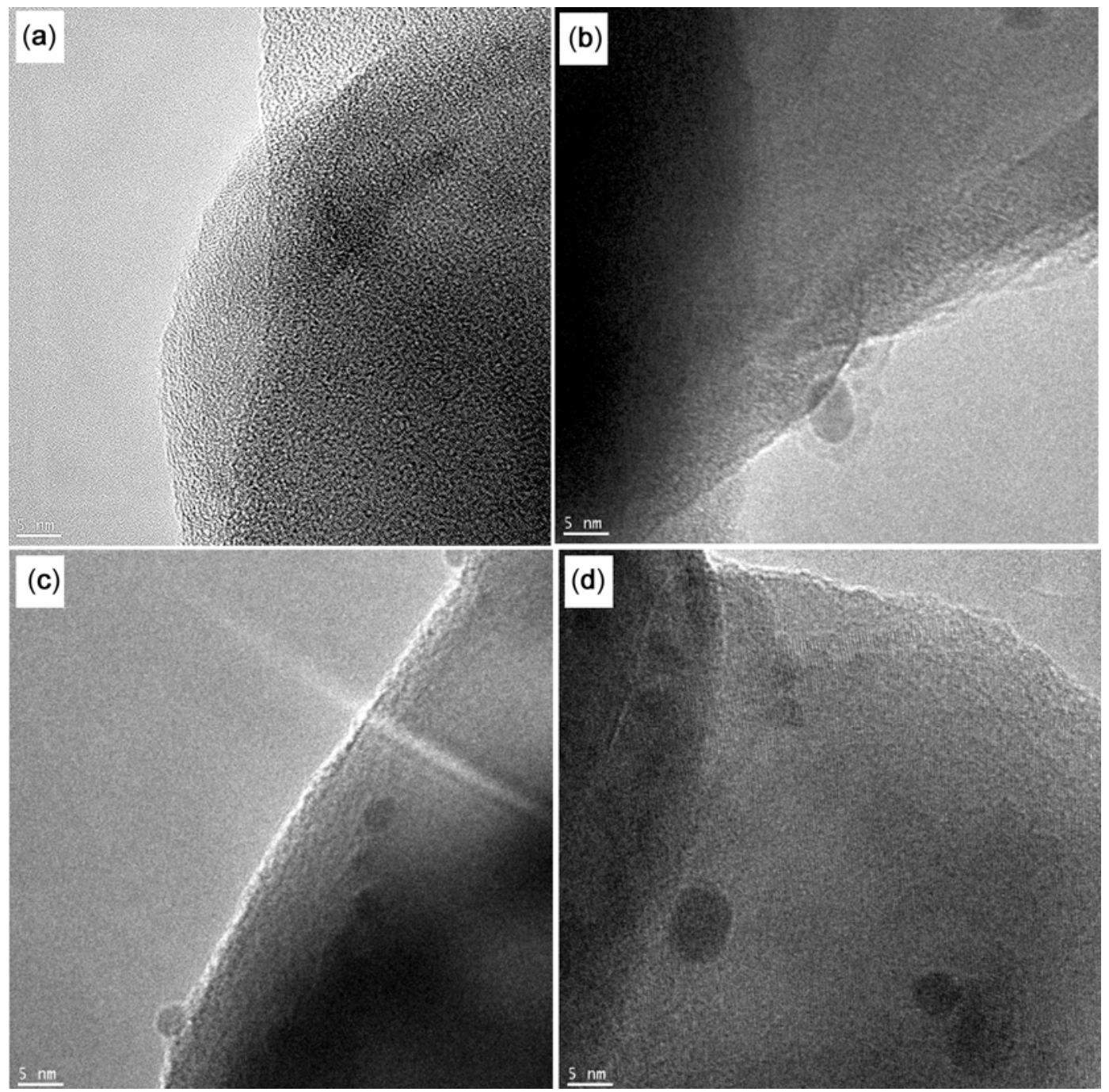

Figure 3. TEM images of unmodified $\mathrm{LiNbO}_{3}$ (a) and $\mathrm{Ag}$-loaded $\mathrm{LiNbO}_{3}$ with 0.5 (b), 2 (c) and 4 (d) $\mathrm{wt} \%$ of $\mathrm{Ag}$.

(700 mL) containing $200 \mathrm{mg}$ of the catalyst. Before light irradiation, nitrogen was bubbled through the reaction mixture for $60 \mathrm{~min}$ to remove dissolved oxygen to ensure that the reaction system is under anaerobic condition. Finally, the solution was irradiated for $150 \mathrm{~min}$ without argon purging. The evolved hydrogen was collected and analysed by a gas chromatography (Chrome 5) equipped with a thermal conductivity detector (TCD).

\section{Results and discussion}

\subsection{Characteristics of produced catalysts}

The crystallographic composition of all investigated samples was studied via XRD. Figure 1 shows XRD patterns of $\mathrm{Nb}_{2} \mathrm{O}_{5}$ original (pattern a) and the materials produced after calcination of $\mathrm{Nb}_{2} \mathrm{O}_{5}$ and $\mathrm{LiOH}$ at a temperature of $550{ }^{\circ} \mathrm{C}$ for different periods $(5,10,15$ and $20 \mathrm{~h}$ - patterns b-e). Figure 1 exhibits that the samples obtained for 5,10 and $15 \mathrm{~h}$ are composed of a mixture of lithium niobate with a rhombohedral structure $\left(\mathrm{LiNbO}_{3}, \mathrm{JCPDS}\right.$ card no. $85-2456)$ and niobium oxide $\left(\mathrm{Nb}_{2} \mathrm{O}_{5}\right)$. However, the relative intensity of the corresponding peaks is altered. When the annealing time increases to $20 \mathrm{~h}$, all the diffraction peaks can be indexed to $\mathrm{LiNbO}_{3}$ and no diffraction peaks from unreacted $\mathrm{Nb}_{2} \mathrm{O}_{5}$ are presented. XRD patterns of unmodified $\mathrm{LiNbO}_{3}$ and $\mathrm{Ag}$-loaded $\mathrm{LiNbO}_{3}$ samples are presented in figure 2 . The detailed phase analysis reveals that $\mathrm{Ag} / \mathrm{LiNbO}_{3}$ photocatalysts contain additional phase of $\mathrm{Ag}_{2} \mathrm{O}$ (JCPDS card no. 03-0796).

The morphology of the samples was studied using HRTEM. Here, only pristine $\mathrm{LiNbO}_{3}$ and three representative Ag-loaded samples with 0.5, 2 and $4 \mathrm{wt} \%$ of Ag will be presented. TEM images for the above mentioned samples are shown in figure 3. TEM analysis reveals high crystallinity in all the investigated samples. Moreover, it can be seen that in $\mathrm{Ag} / \mathrm{LiNbO}_{3}$ samples (images b-d), new phase is dispersed. The new phase can be attributed 

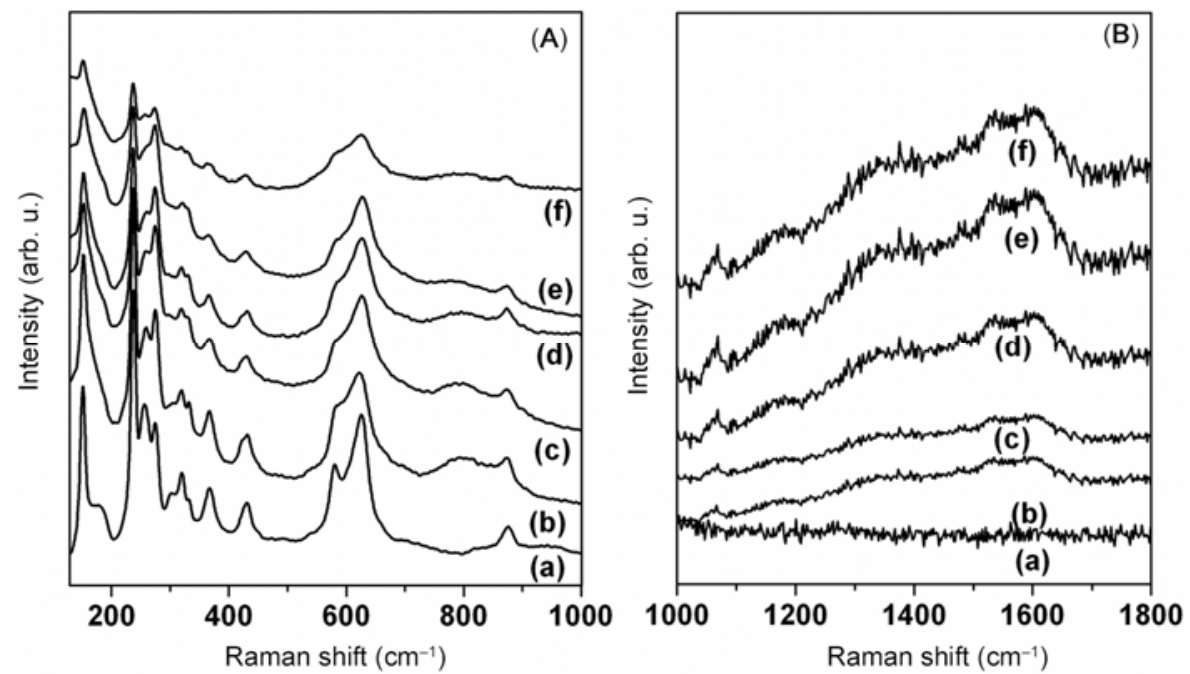

Figure 4. Raman spectra of samples: $\mathrm{LiNbO}_{3}$ (a) and $\mathrm{Ag}$-loaded $\mathrm{LiNbO}_{3}$ with $0 \cdot 5$ (b), 1 (c), 2 (d), 3 (e) and 4 (f) wt\% of Ag.
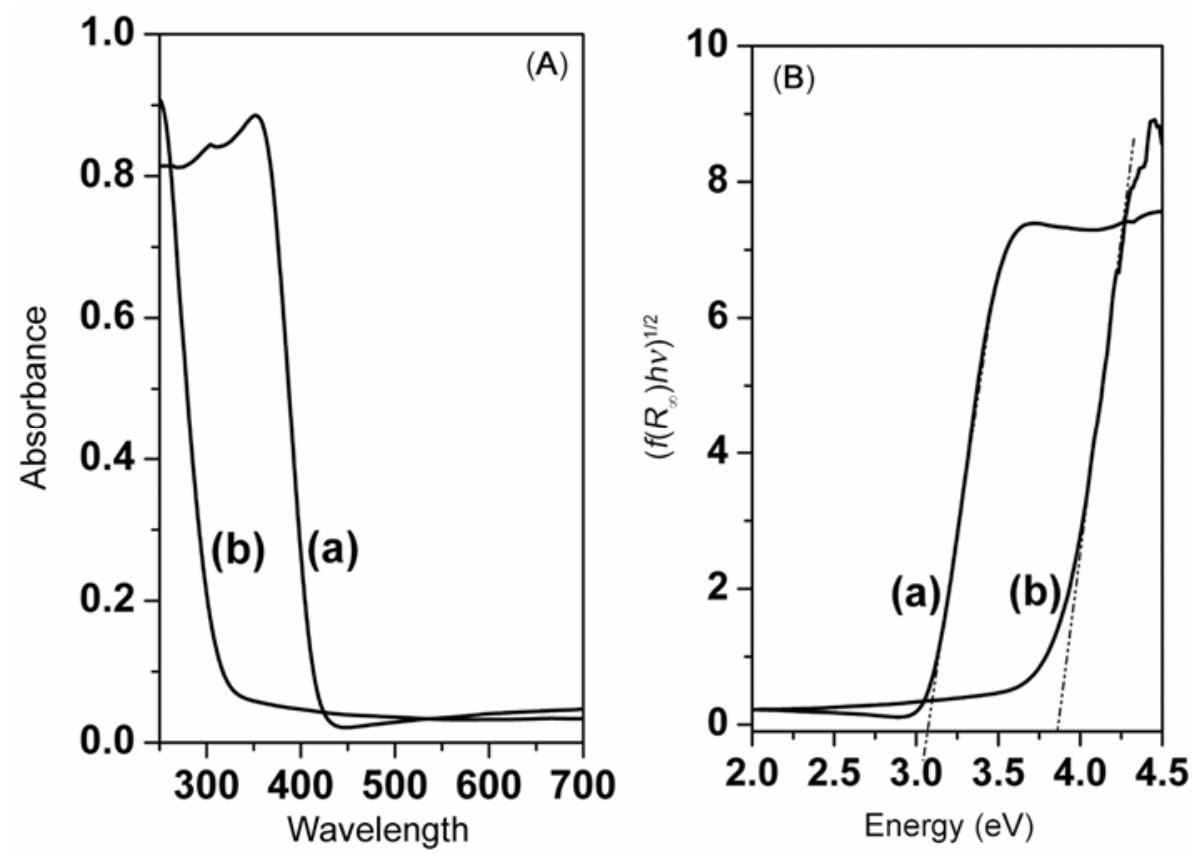

Figure 5. Diffuse reflectance UV-Vis absorption spectra (A) and Kubelka-Munk plot for bandgap evaluation (B) of $\mathrm{Nb}_{2} \mathrm{O}_{5}$ (a) and $\mathrm{LiNbO}_{3}(\mathbf{b})$.

to $\mathrm{Ag}_{2} \mathrm{O}$ and is composed of the nanoparticles in the range of $2-5 \mathrm{~nm}$. These results are consistent with XRD measurements.

Next, the samples were investigated by means of Raman spectroscopy. Figure 4(A) shows Raman spectra of the unmodified $\mathrm{LiNbO}_{3}$ (spectrum a) and Ag-loaded $\mathrm{LiNbO}_{3}$ samples (spectra $\mathrm{b}-\mathrm{f}$ ) in the region between 100 and $1000 \mathrm{~cm}^{-1}$. The clear Raman bands at 151, 237, 257, $275,319,368,430,580,626$ and $874 \mathrm{~cm}^{-1}$ can be observed for $\mathrm{LiNbO}_{3}$. In the spectra of $\mathrm{Ag} / \mathrm{LiNbO}_{3}$ all bands characteristic for $\mathrm{LiNbO}_{3}$ have also been observed. Moreover, in figure 4(A), a new broad band in the region of $730-850 \mathrm{~cm}^{-1}\left(\sim 790 \mathrm{~cm}^{-1}\right)$ is detected for $\mathrm{Ag} / \mathrm{LiNbO}$ samples. Raman spectra of all investigated samples in the range of 1000 and $1800 \mathrm{~cm}^{-1}$ are shown in figure 4(B). No Raman modes in the region of 1000 and $1800 \mathrm{~cm}^{-1}$ have been detected for $\mathrm{LiNbO}_{3}$. Here, one can notice that in $\mathrm{Ag} / \mathrm{LiNbO}_{3}$ spectra new Raman modes at about $1060 \mathrm{~cm}^{-1}$ and a split broad band in the region of 1437 $1690 \mathrm{~cm}^{-1}$ are observed. All those peaks are characteristic 
for $\mathrm{Ag}_{2} \mathrm{O}$. Raman spectrum of $\mathrm{Ag}_{2} \mathrm{O}$ exhibited five bands at 251, 722, 1042, 1465 and $1959 \mathrm{~cm}^{-1}$ (Mohammed et al 2012). The peaks at 251 and $1042 \mathrm{~cm}^{-1}$ in Raman spectrum of $\mathrm{Ag}_{2} \mathrm{O}$ are related to the stretching $(\mathrm{Ag}-\mathrm{O})$ mode between $\mathrm{Ag}$ and $\mathrm{O}$ atoms. Here, clear agreement with XRD data is demonstrated.

DR-UV-Vis absorption spectra were measured in order to characterize optical properties of $\mathrm{Nb}_{2} \mathrm{O}_{5}, \mathrm{LiNbO}_{3}$ and $\mathrm{Ag} / \mathrm{LiNbO}_{3}$ samples. To determine the bandgap energy of the investigated samples, the Kubelka-Munk method based on DR-UV-Vis spectra was employed. Greater details of the bandgap energy estimations have

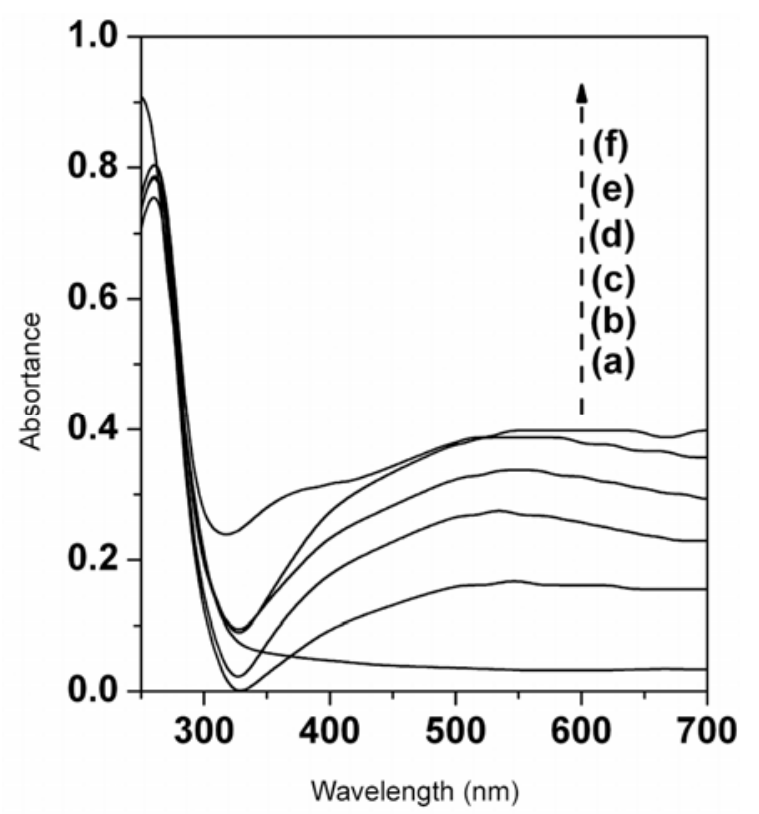

Figure 6. UV-Vis spectra of samples: $\mathrm{LiNbO}_{3}$ (a) and Ag-loaded $\mathrm{LiNbO}_{3}$ with 0.5 (b), 1 (c), 2 (d), 3 (e) and 4 (f) wt $\%$ of Ag.

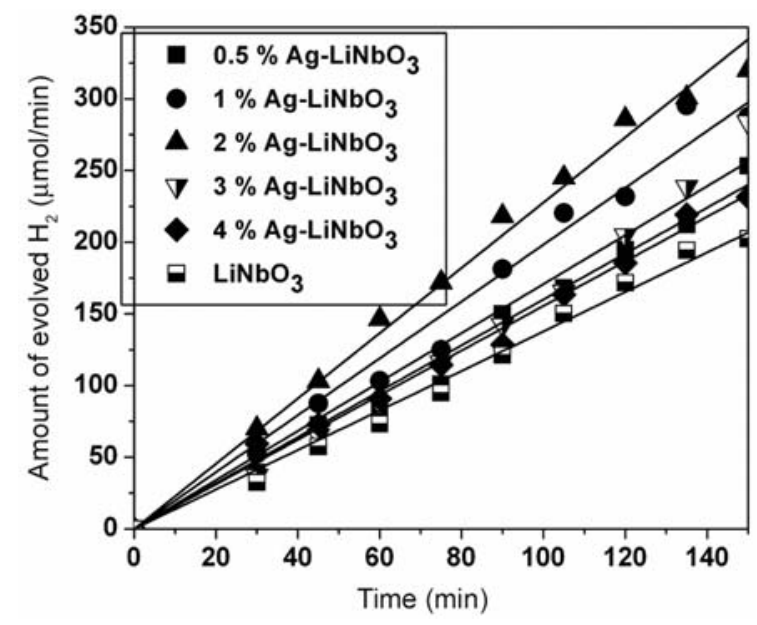

Figure 7. Photocatalytic $\mathrm{H}_{2}$ evolution over $\mathrm{LiNbO}_{3}$ and $\mathrm{Ag}$ loaded $\mathrm{LiNbO}_{3}$ catalysts $(\mathrm{HCOOH}$ concentration $-0.1 \mathrm{moL} /$ $\mathrm{dm}^{3}$, amount of catalysts $-0 \cdot 2 \mathrm{~g}$ ). been provided in the literature (Zielińska et al 2011). Figure 5 shows DR-UV-Vis spectra of the pristine $\mathrm{Nb}_{2} \mathrm{O}_{5}$ (spectrum a) and produced $\mathrm{LiNbO}_{3}$ (spectrum b). This figure presents two plots: A and B. Figure 5(A) shows absorption spectra while figure $5(\mathrm{~B})$ illustrates the plot of $(F(R) h v)^{1 / 2}$ vs photon energy $(h v)$ for $\mathrm{Nb}_{2} \mathrm{O}_{5}$ and $\mathrm{LiNbO}_{3}$. As shown in this figure, a single absorption edge can be clearly observed for $\mathrm{Nb}_{2} \mathrm{O}_{5}$ and $\mathrm{LiNbO}_{3}$. Moreover, the absorption edge of $\mathrm{LiNbO}_{3}$ is shifted towards the shorter wavelength in respect to $\mathrm{Nb}_{2} \mathrm{O}_{5}$. It indicates that the blue shift of the bandgap energy occurred. The estimated bandgap energy of $\mathrm{Nb}_{2} \mathrm{O}_{5}$ and $\mathrm{LiNbO}_{3}$ samples are 3.07 and $3.86 \mathrm{eV}$. The estimated value of bandgap of produced $\mathrm{LiNbO}_{3}$ is similar to that described in the literature (Hao et al 2011; Tiwari and Dunn 2012). DR-UVVis spectra of $\mathrm{Ag} / \mathrm{LiNbO}_{3}$ samples are presented in figure 6. Here one can notice that all $\mathrm{Ag} / \mathrm{LiNbO}$ samples have strong absorption in the visible light region with respect to the starting $\mathrm{LiNbO}_{3}$. This is characteristic for $\mathrm{Ag}_{2} \mathrm{O}$ (Wang et al 2011). The reported values of the bandgap of $\mathrm{Ag}_{2} \mathrm{O}$ based on optical absorption edge ranges from 0.49 to $3 \cdot 1 \mathrm{eV}$ (Fang et al 2011). This is in full agreement with XRD and Raman data of the presented samples.

\subsection{Photocatalytic reactions}

The photocatalytic hydrogen production studies were conducted over unmodified $\mathrm{LiNbO}_{3}$ and silver modified $\mathrm{LiNbO}_{3}$ catalysts in formic acid-water mixture under UV light irradiation. The comparison of hydrogen evolution over $\mathrm{LiNbO}_{3}$ and $\mathrm{Ag} / \mathrm{LiNbO}_{3}$ photocatalysts is presented in figure 7. It can be seen that silver loading improved the photocatalytic activity of $\mathrm{LiNbO}_{3}$. The explanation of higher photocatalytic activity of Ag-loaded $\mathrm{LiNbO}_{3}$ than that of unmodified $\mathrm{LiNbO}_{3}$ can be explained by the higher electronegativity of $\mathrm{Ag}(1.93)$ as compared to that of $\mathrm{Nb}$ (1.60), resulting in easier photoexcited electron transfer from $\mathrm{LiNbO}_{3}$ conduction band to the $\mathrm{Ag}$ species. This efficient electron transfer can inhibit rapid recombination of electron-hole pairs, leading to higher activity of $\mathrm{Ag} / \mathrm{LiNbO}_{3}$ composites for photocatalytic hydrogen production. Moreover, it is possible that for Ag-loaded $\mathrm{LiNbO}_{3}$ catalysts silver species works as active sites for proton reduction (Puangpetch et al 2010; Onsuratoom et al 2011). Based on the obtained results a possible mechanism of photocatalytic hydrogen generation from aqueous solution of formic acid and over $\mathrm{Ag} / \mathrm{LiNbO}$ is proposed below (1-6) (Zheng et al 2009; Zheng et al 2010):

$$
\begin{aligned}
& \mathrm{Ag} / \mathrm{LiNbO}_{3} \stackrel{h v}{\longrightarrow} e^{-}+h^{+}, \\
& \mathrm{H}_{2} \mathrm{O}+h^{+} \rightarrow \mathrm{H}^{+}+{ }^{\bullet} \mathrm{OH}, \\
& { }^{\circ} \mathrm{OH}+{ }^{\bullet} \mathrm{OH} \rightarrow \mathrm{H}_{2} \mathrm{O}+1 / 2 \mathrm{O}_{2},
\end{aligned}
$$




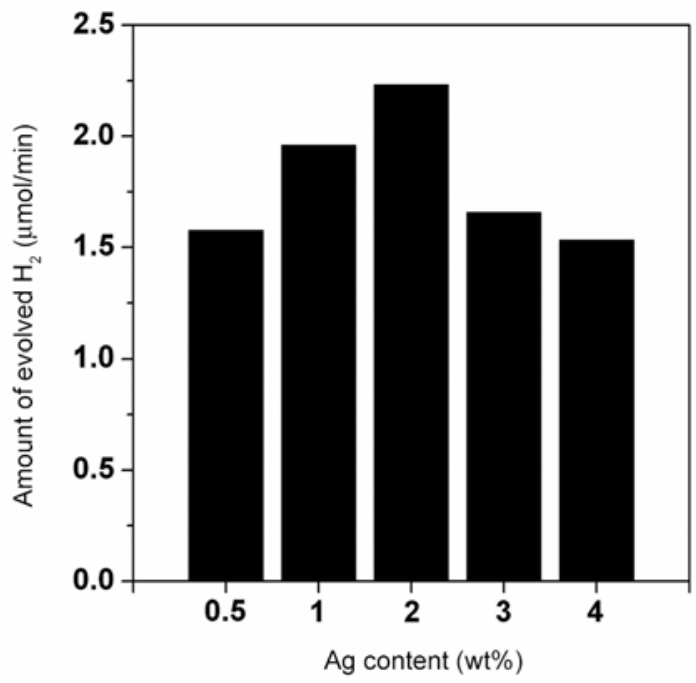

Figure 8. Effect of $\mathrm{Ag}$ content in catalysts on $\mathrm{H}_{2}$ evolution rate.

$$
\begin{aligned}
& \mathrm{HCOOH} \rightarrow \mathrm{HCOO}^{-}+\mathrm{H}^{+}, \\
& \mathrm{HCOO}^{-}+2 h^{+} \rightarrow \mathrm{H}^{+}+\mathrm{CO}_{2} \uparrow, \\
& 2 \mathrm{H}^{+}+2 e^{-} \rightarrow \mathrm{H}_{2} \uparrow .
\end{aligned}
$$

In the initial stage (1), light is absorbed by photocatalysts to produce electron-hole pairs. The molecules of water in the formic acid solution split into hydroxyl radicals $\left({ }^{\circ} \mathrm{OH}\right)$ and $\mathrm{H}^{+}$ions through $\mathrm{H}_{2} \mathrm{O}$ oxidation (2). The hydroxyl radicals thus obtained generate molecular water and oxygen (3). In the next step (4-5), $\mathrm{HCOOH}$ dissociates to $\mathrm{HCOO}^{-}$and $\mathrm{H}^{+}$ions. The photogenerated holes attack the produced $\mathrm{HCOO}^{-}$to form $\mathrm{H}^{+}$and $\mathrm{CO}_{2} \cdot \mathrm{H}^{+}$ions produced during whole process (2 and 4) transfer to the loaded-Ag species, where reduction to $\mathrm{H}_{2}$ by photogenerated electrons occurred (6).

The presented results clearly indicate that the kinetics of hydrogen generation during the first $150 \mathrm{~min}$ of irradiation can be described by zero-order kinetics. The effect of $\mathrm{Ag}$ content in catalysts on $\mathrm{H}_{2}$ evolution rate is presented in figure 8 . Here, the amount of released hydrogen increases when the content of $\mathrm{Ag}$ increases from 0.5 to $2 \mathrm{wt} \%$. As the amount of loaded silver was $>2 \mathrm{wt} \%$, the activity of modified materials were decreased. The amount of the generated hydrogen increased from $1.57 \mu \mathrm{mol} / \mathrm{min}\left(0.5 \mathrm{wt} \%-\mathrm{Ag} / \mathrm{LiNbO}_{3}\right)$ to $2.28 \mu \mathrm{mol} / \mathrm{min}$ $\left(2 \mathrm{wt} \%-\mathrm{Ag} / \mathrm{LiNbO}{ }_{3}\right.$ ) and then decreased to $1.53 \mu \mathrm{mol} /$ min $\left(4 \mathrm{wt} \%-\mathrm{Ag} / \mathrm{LiNbO}_{3}\right)$. This effect can be explained by the partial blockage of $\mathrm{LiNbO}_{3}$ surface active sites due to excessive amount of silver species (Hao et al 2011). Moreover, it is possible that at high $\mathrm{Ag}$ content, $\mathrm{Ag}_{2} \mathrm{O}$ would tend to aggregate into larger particles which results in a negative impact on $\mathrm{Ag} / \mathrm{LiNbO}_{3}$ composite activity (Long et al 2006; Hao et al 2011; Tran et al 2012).

\section{Conclusions}

The synthesis and detailed characterization of unmodified $\mathrm{LiNbO}_{3}$ and Ag-loaded $\mathrm{LiNbO}_{3}$ photocatalysts were described. Moreover, the activities in the reaction of photocatalytic hydrogen evolution in the presence of formic acid of unmodified $\mathrm{LiNbO}_{3}$ and $\mathrm{Ag}$-loaded $\mathrm{LiNbO}_{3}$ samples have been shown. The following conclusions are provided: (i) pure $\mathrm{LiNbO}_{3}$ was synthesized after calcination of $\mathrm{Nb}_{2} \mathrm{O}_{5}$ and $\mathrm{LiOH}$ at the temperature of $550{ }^{\circ} \mathrm{C}$ for $20 \mathrm{~h}$, (ii) $\mathrm{Ag}_{2} \mathrm{O}$ oxides on $\mathrm{Ag} / \mathrm{LiNbO}_{3}$ was confirmed, (iii) a significant enhancement of the photocatalytic efficiency of Ag-loaded $\mathrm{LiNbO}_{3}$ as compared to unmodified $\mathrm{LiNbO}_{3}$ was observed and (iv) the highest $\mathrm{H}_{2}$ evolution efficiency was observed for $\mathrm{Ag} / \mathrm{LiNbO}_{3}$ photocatalyst with $2 \mathrm{wt} \%$ silver content.

\section{References}

An Ch, Tang K, Wang Ch, Shen G, Jin Y and Qian Y 2002 Mater. Res. Bull. 371791

Chen Q Y, Yang Y H, Yin Z L, Chen Q, Yang Y, Yin Z, Li J and Liang S 2004 Trans. Nonferrous. Met. Soc. China 14798

Chen Y, Yang H, Liu X and Guo L 2010 Int. J. Hydrogen Energ. 357029

Chen $\mathrm{Z}$ et al 2012 RSC Advances 27380

Fang F, Li Q and Shang J K 2011 Surf. Coat. Technol. 2052919

Hao L Z et al 2011 Chinese Phys. Lett. 28107703

Hao L, Zhu J, Luo W, Zeng H, Li Y, Huang W, Liao X and Zhang Y 2009 Appl. Phys. Lett. 95232907

Kudo A 2006 Int. J. Hydrogen Energ. 31197

Liu M and Xue D 2006 Solid State Ionics 177275

Long M, Cai W, Cai J, Zhou B, Chai X and Wu Y 2006 J. Phys. Chem. B110 20211

Mohammed M, Rahman K, Bahadar S, Jamal A, Faisal M and Asiri A M 2012 Chem. Eng. J. 192122

Onsuratoom S, Puangpetch T and Chavadej S 2011 Chem. Eng. J. 173667

Puangpetch T, Sreethawong T and Chavadej S 2010 Int. J. Hydrogen Energ. 356531

Saito K, Koga K and Kudo A 2011 Dalton Trans. 403909

Simoes A Z, Gonzalez A H M, Ries A, Zaghete M A, Stojanovic B D and Varela J A 2003 Mater. Charact. 50239

Stock M and Dunn S 2012 J. Phys. Chem. C116 20854

Tiwari D and Dunn S 2012 Mater. Lett. 7918

Tran P D, Xi L, Batabyal S K, Wong L H, Barber J and Loo J S C 2012 Phys. Chem. Chem. Phys. 1411596

Wang X, Li S, Yu H, Yu J and Liu S 2011 Chem. Eur. J. 17 7777

Yu J, Hai Y and Jaroniec M 2011 J. Colloid Interf. Sci. 357223

Zheng X J, Wei L F, Zhang Z H, Jiang Q J, Wei Y J, Xie B and Wei M B 2009 Int. J. Hydrogen Energ. 349033

Zheng X J, Wei Y J, Wei L F, Xie B and Wei M B 2010 Int. J. Hydrogen Energ. 3511709

Zielińska B, Borowiak-Palen E and Kalenczuk R J 2008 J. Phys. Chem. Solids 69236

Zielińska B, Borowiak-Palen E and Kalenczuk R K 2011 J. Phys. Chem. Solids $\mathbf{7 2} 117$ 